\title{
Performance Comparison of Cold in Place Recycled and Conventional HMA Mixes
}

\author{
Kamran Muzaffar Khan ${ }^{1}$, Mumtaz Ahmed Kamal ${ }^{2}$, Faizan Ali ${ }^{3}$, Shiraz \\ Ahmed $^{4}$, Tahir Sultan ${ }^{5}$ \\ ${ }^{1}$ Associate Professor, Civil Engineering Department, UET Taxila, Pakistan \\ ${ }^{2}$ Professor, Dean of Faculty of Civil and Environmental Engineering, UET Taxila, Pakistan \\ ${ }^{3,4}$ Research Associate, Civil Engineering Department, UET Taxila, Pakistan \\ ${ }^{5}$ Assistant professor, BZU Multan, Pakistan
}

\begin{abstract}
Cold In-Place Recycling (CIR) of flexible pavements has been experimented and executed worldwide during the past twenty years. The performance of CIR projects is inconsistent in different parts of the world; furthermore its mix design is still under development. In local traffic and climatic conditions of Pakistan, this research work was focused to evaluate the structural performance of cold in-placed recycled mixes. This will assist the highway agencies of the country for making decision regarding future utilization of cold recycling technology, especially in the conditions of budgetary constraints for maintenance and rehabilitation and expanding highway network. For the structural evaluation of CIR pavements, Resilient Modulus Test and Static Creep test was performed on Marshall Samples of CIR mixes using UTM -5P with Cement and Lime being used as an additive at various temperatures and loading Frequencies and their strength was compared with conventional HMA mixes. It was concluded that the performance of cold recycling and conventional rehabilitation was nearly the same and the cement added cold recycled mixes were found better than lime added.
\end{abstract}

Key Words: Additives, Cold in Place recycling, Pavement Rehabilitation, UTM 5P.

\section{Introduction}

Road Transportation system is one of the key components in social and economic development of a country and it takes a considerable amount of national budget. Pakistan, with more than 180 million people, has a reasonably developed transport infrastructure. Road transport is the backbone of Pakistan's transport system.

The current road density of Pakistan is $0.32 \mathrm{Km} / \mathrm{Sq} \cdot \mathrm{Km}$ with total road network of $260,000 \mathrm{Km}$ (Both high and low type). It is much less even from regional standards; the road density of India is approximately 1.00. The maximum value of road density is of Japan, which is approximately 3.07. (Pakistan Economic Survey, 2009-10). Pakistan is endeavoring hard to double its road density, which is possible, only if maintenance and rehabilitation expenditure is controlled to an acceptable limit.

National Highway Authority has been experimenting new maintenance and rehabilitation techniques, including hot and cold recycling, to meet the demands of growing road network with scarce resources. Approximately Rs. 18.961 billion are required for annual maintenance of highways, where as Rs. 13.774 billions is estimated for periodic maintenance (structural and functional overlay), and about Rs. 5.187 billion for routine maintenance, highway safety, and other maintenance schemes. But NHA has resources of only Rs. 13 Billion for FY 2009-10. It is anticipated that if additional funds are not provided there would be maintenance backlog during 1- 3 years time. (NHA, AMP 2009-10).

Construction materials preservation, environment friendly construction, speedy and cost effective rehabilitation alternatives are the requirements of current age. Road roughness and condition surveys on NHA network have revealed that conventional methods of maintenance and rehabilitation could not perform up to the mark in the past due to several reasons; especially labour factor (Human) for patch works and quality control issues associated with bitmac and even with pre-mix asphalt overlays in the small rehabilitation stretches far-off from the Asphalt Plant. In contrary, by adopting new techniques of asphalt pavement recycling, particularly cold in place recycling, a quality controlled final product could be targeted using latest equipment i.e. Cold Recycler along with recycling train.

Cold in-place recycling (CIR) is being considered to be an efficient and effective method in the developed countries for rehabilitating asphalt roads showing non-structural aging and cracking of the pavement layer. It has been noticed in most parts of the world that CIR is unpredictable, roads recycled under similar weather and construction conditions perform entirely different for no clear reason. Moreover, a rational mix design has not yet been developed, and there is no clear understanding of the cause-effect relationships between the choices made during the design/ construction process and the resulting 
performance. Past laboratory and field test results indicate that method of curing, temperature, and duration of the curing significantly affect the properties of CIR mixtures.

The research objectives were to explore different cost effective, having improved pavement performance and environment friendly additives and fillers to be used in CIR, and to;

- Study the performance of CIR pavements with different additives.

- Compare the Performance of Cold In Place Recycled and Conventional HMA mixes by MR Test and Indirect tensile Strength Test

\section{Literature Review}

With the passage of time naturally available construction materials i.e. available as in the form of natural quarries, are becoming scarce. Pavement recycling is one of the technique by which one can address the scarcity of the natural material. In pavement recycling we use the aggregates obtained by cutting and milling of the existing pavement and by doing this we not only conserve the virgin aggregates but also save million of rupees. Recycle pavements behave in the same way as that the new Pavement, if properly constructed and design. More than 73 million ton of the material is being recycled by USA pavement industry [1]. Several recycling techniques, has been introduced during the past 35 years. Cold in Place recycling is one of them, and it is environmental friendly, utilizes fewer amounts of fuel and as well as faster construction.

The selection of most appropriate method of an Asphalt Pavement Recycling based on various factors, the most suitable process of recycling, its applicability and few important engineering considerations are summarized below:

Table 1: Most Appropriate method of Asphalt Pavement Recycling [1]

\begin{tabular}{|l|l|l|}
\hline PROCESS & APPLICABILITY & CONSIDERATIONS \\
\hline $\begin{array}{l}\text { Hot Mix Asphalt } \\
\text { Recycling } \\
\text { (Central plant) }\end{array}$ & $\begin{array}{l}\text { Surface defects, Deformations, } \\
\text { Cracks, Maintenance patching }\end{array}$ & $\begin{array}{l}\text { Percentage of RAP depends on recycled } \\
\text { mix properties and type of plant }\end{array}$ \\
\hline Hot In-place & $\begin{array}{l}\text { Surface defects, Corrugation, } \\
\text { Surface rutting, Longitudinal } \\
\text { and Slippage crack }\end{array}$ & $\begin{array}{l}\text { Sufficient amount of work and space for } \\
\text { maneuvering of equipment is required; } \\
\text { crack sealing material can cause smoke }\end{array}$ \\
\hline $\begin{array}{l}\text { Cold Mix Recycling } \\
\text { (Central plant) }\end{array}$ & $\begin{array}{l}\text { All types of cracks except } \\
\text { fatigue and those caused by } \\
\text { base failures }\end{array}$ & $\begin{array}{l}\text { May require aeration before compaction } \\
\text { to reduce moisture; wearing surface } \\
\text { normally required }\end{array}$ \\
\hline Cold In-place & $\begin{array}{l}\text { Rutting in sub-surface layers, } \\
\text { Load associated cracks, } \\
\text { Maintenance patching }\end{array}$ & $\begin{array}{l}\text { May require curing period, followed by } \\
\text { application of wearing surface; bigger } \\
\text { equipment train needs more maneuvering } \\
\text { space }\end{array}$ \\
\hline $\begin{array}{l}\text { Full Depth } \\
\text { Reclamation }\end{array}$ & $\begin{array}{l}\text { Rutting in sub- surface layers } \\
\text { Roads with base problems or } \\
\text { insufficient structural capacity }\end{array}$ & $\begin{array}{l}\text { Requires wearing course; may require } \\
\text { significant amount of curing time; lack of } \\
\text { proper guidelines; experienced }\end{array}$ \\
\hline
\end{tabular}

\subsection{Cold In-place Recycling (CIR)}

In this process existing pavement materials are removed, mixed with stabilizing agents, virgin materials (if required) and reused in place. Cold in-place recycling is conducted on site and generally uses 100 percent of the RAP generated during the process. Some of the advantages associated with Cold in Place recycling are given below;

- The same pavement can be recycled over and over again

- Provides significant structural improvements.

- Treats all types and degrees of pavement distress.

- Can eliminate reflection cracking.

- May improve frost susceptibility.

- Improves ride quality.

- Improves skid resistance.

To know about the effect of different asphalt binders, amount of reclaimed asphalt pavement used and aging of RAP, dynamic creep test was conducted by Guiping et al to evaluate the behavior of foamed asphalt mixes [2]. Creep strain slope, intercept and secant creep stiffness modulus has been taken into account during the test. Creep strain slope has been greatly affected by grade of bitumen. While percentage 
and aging of RAP did not have much effect on the creep strain slope (CSS). It was concluded that Foam Asphalt Mixes were better than hot asphalt samples in susceptibility and creep strength.

By following empirical mechanistic approach six different asphalt mixes containing reclaimed asphalt pavement material were evaluated. Determination of mechanical properties, strength of wearing and base course at different Percentages of RAP and evaluation of rheology of binders were determined. It was concluded that recycled mixes showed same results and in some cases better than conventional mixes. [3] Niazi et al used different additives to check the behavior of cold in place mixes. For this purpose Portland cement, hydrated lime as powder and slurry were used. Against different properties such as resistance to permanent deformation, Marshall Stability, Tensile strength and resilient modulus, cement and lime added mixes showed better results than neat samples. Further among different additives the use of Portland cement was recommended. [4]

Hamad et al studied the effect of characteristics of asphalt foam and PAP (Pulverized Asphalt Pavement) material attributing the strength of mix. A fracture face image analysis procedure was used to quantify asphalt dispersion. It was found that foamability of asphalt was one of the primary factors determining the quality of mix. Foams with higher expansion ratios and longer half-life have better dispersion through granular materials, resulting in greater strength improvement. High fine contents in the PAP materials have a negative effect on mix strength as they produce a continuous and weak unbounded mineral filler phase. The micro structural analysis found that the physical and chemical analysis of the PAP material should be done for every project because they significantly affect the dispersion of foam and mix strength. [5]

Pengcheng et al investigated the behavior of foamed asphalt mixes against conventional crush aggregates for road bases. This work was conducted to find out the suitable recycled mix design using foam bitumen and RAP that behaves well in the climatic and loading conditions of Saudi Arabia. Design mixes were prepared using different gradations i.e. Granular Base Class A and B, Subbase material Class B and Reclaimed Asphalt pavement material (RAP). Foamed RAP showed lowest rutting at soaked condition and foamed rap behaves best in resilient modulus testing. [6]

This research was carried out to check the behavior of steel slag by substituting virgin aggregate on the properties of cold recycled pavement mixes. For satisfying gradation requirement of two different RAP material $20 \%$ and $10 \%$ of the steel slag was added. It has been shown that by adding steel slag resistance to deformation, Marshall Stability, resilient Modulus and tensile strength has improved. [7]

\section{Methodology}

In the current study the performance of cold recycled mixes were evaluated by resilience modulus test and repeated load uniaxial strain test (Static Creep) ASTM D 4123.

Resilient modulus is the key parameter in mechanistic design of asphalt pavements, based on elastic theory. Resilient modulus of bituminous mixes was determined in accordance with ASTM D4123 standard specification, is the most accepted form of stress-strain measurements used to estimate the elastic properties of these mixes.

Table 2. Testing conditions for Modulus of Resilience test.

\begin{tabular}{|l|l|l|}
\hline S. No. & Conditions & Values \\
\hline $\mathbf{1}$ & Temperature & $50 \mathrm{C}$ \\
\hline $\mathbf{2}$ & Total pulse period & $1000 \mathrm{~ms}$ \\
\hline $\mathbf{3}$ & Pulse width & $500 \mathrm{~ms}$ \\
\hline $\mathbf{4}$ & Peak Loading & 300 \\
\hline $\mathbf{5}$ & Poisson Ratio & 0.40 \\
\hline
\end{tabular}

8 samples were tested at the above mentioned conditions. Out of these 8 samples, 3 were cement added samples, 3 were lime added samples and the remaining 2 samples were conventional HMA mixes.

C-Class Gradation (MS-21 Recycling Note) was used for Recycled Mixes, Cement and Lime content of $2 \%(24 \mathrm{~g})$ is used for recycled mixes (8 Samples each) and for Conventional mixes A-Class gradation (NHA) is used with Bitumen content of $4 \%$. Following figure shows the gradation for both type of mixes. 


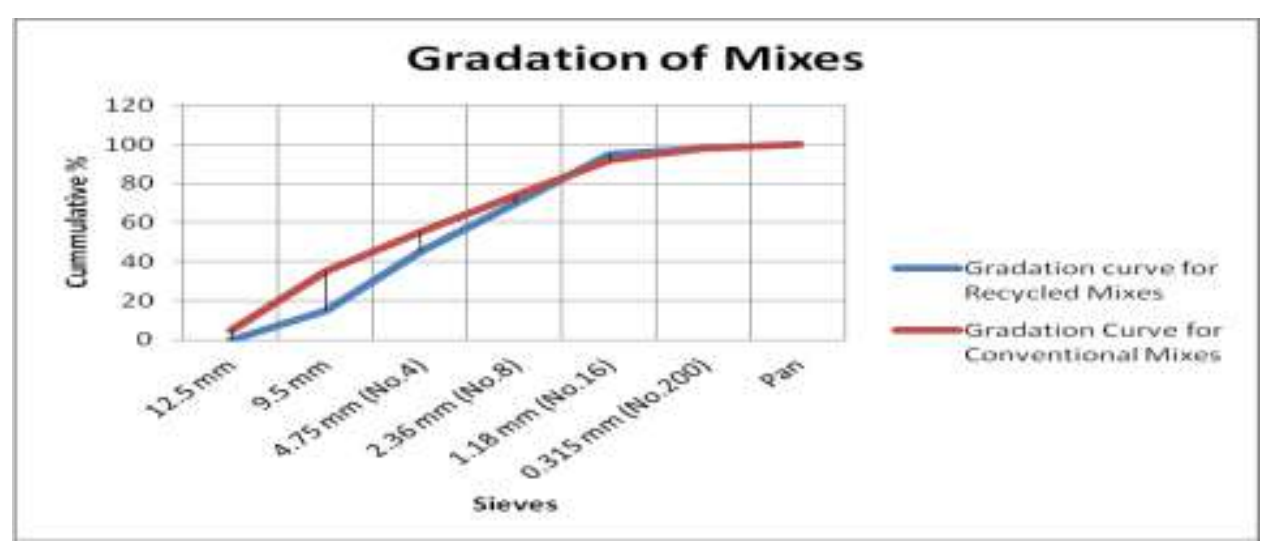

Figure 1: Gradation for both type of Mixes

Repeated load uniaxial strain test was performed on the cores at $100 \mathrm{kPa}$ loading stress and at 40 and 50 temperatures considering the temperatures and loading conditions in Pakistan. The loading pulse period of $1000 \mathrm{~ms}$ and pulse width of $500 \mathrm{~ms}(.5 \mathrm{sec})$ was selected. This test conforms to the requirements of the design draft issued by the British standards Institute as a method of measurement of resistance to permanent deformation of bitumen mixtures that are subjected to unconfined uniaxial repeated loading. The test initially applies a static conditioning stress to the specimen and measures the resulting accumulating strain.

Figure 2 is showing the average modulus of resilience (Mr) values of all the three types of mixes. Figure 3 and Figure 4 are showing the results of Creep stiffness of all the mixes.

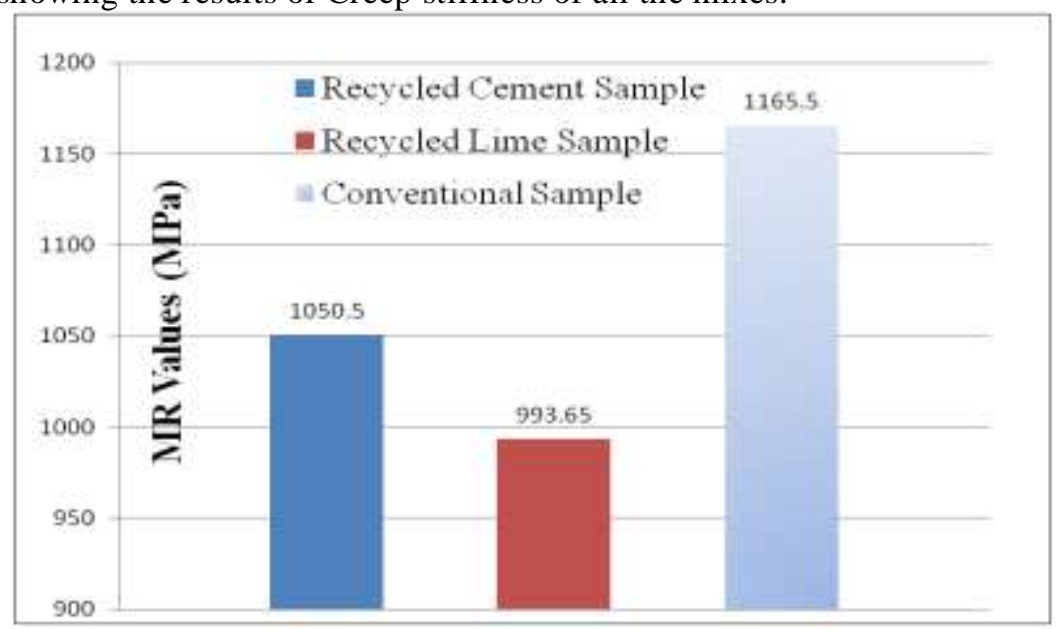

Figure 2: Mr Values of the three mixes

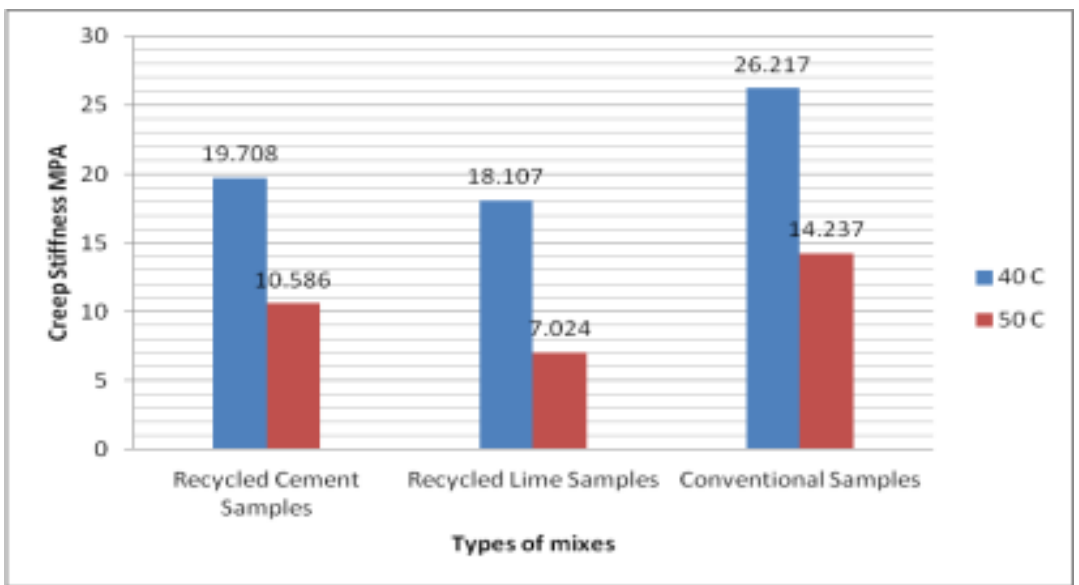

Figure 3. Creep stiffness values at $40 \mathrm{C}$ and $50 \mathrm{C}$ 


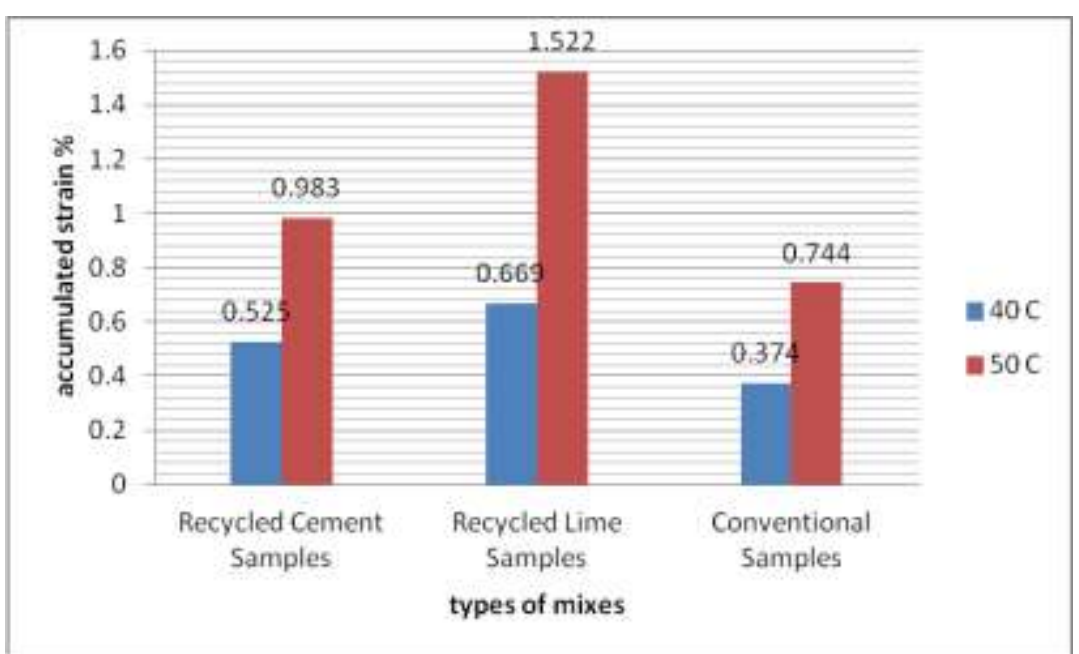

Figure 4: Accumulated strain values at $40 \mathrm{C}$ and $50 \mathrm{C}$

From figure 2. It can be seen that the addition of additives in CIR mixes produces higher resilient modulus with cement as compared with lime. The values of resilient modulus for both CIR lime and CIR cement mixes are less than the conventional HMA mixes but are comparable.

The results of creep test indicates that at the same loading conditions, the accumulated strain increases with the increase in temperature and the creep stiffness decreases with the increase in temperature for both recycled and conventional HMA mixes. The conventional mixes showed better results i.e. less strain and high creep stiffness at both temperatures conditions.

\section{Conclusions}

- There is no significant difference between the values of CIR mixes and conventional HMA mixes in case of both MR and Creep test.

- The strength of cement mixes are more as compared to the lime mixes because of its high strength properties.

- The conventional mixes in both the tests gives better values than the recycled mixes but being cost effective and environmental friendly technique the results of recycled mixes are acceptable.

\section{References:}

[1] Asphalt Recycling and Reclaiming Association, Federal Highway Administration, US Department of Transportation, Basic Asphalt Recycling Manual. United States, 2001.

[2] He Gui-ping et al, "Laboratory Study on permanent deformation of foamed asphalt mix incorporating reclaimed Asphalt pavement materials" Construction and Building Materials 21 (2007) 1809-1819.

[3] Iswandaru Widyatmoko, "Mechanistic-Empirical Mixture design for hot mix asphalt pavement recycling". Construction and Building Materials 22 (2008) 77-87

[4] Y. Niazi et al, "Effect of Portland cement and lime additives on properties of cold in-place recycled mixtures with asphalt emulsion" Construction and Building Materials 23 (2009) 1338-1343

[5] Hamad I. Al-Abdul Wahhab et al, "Study of road bases construction in Saudi Arabia using foam asphalt" Construction and Building Materials xxx (2011) xxx-xxx (Article in press).

[6] Pengcheng $\mathrm{Fu}$ et al, "The effects of asphalt binder and granular material characteristics on foamed as phalt mix strength" Construction and Building Materials 25 (2011) 1093-1101

[7] Mahmoud Ameri et al, "Laboratory studies to investigate the properties of CIR mixes containing steel slag as a substitute for virgin aggregates" Construction and Building Materials 26 (2012) 475-480 